\title{
Promoting photonics: it is up to all of us
}

\author{
John M. Dudley* \\ Université Bourgogne-Franche-Comté-CNRS UMR 6174, Institut FEMTO-ST, Besançon, France
}

As workers in photonics, we are intimately aware of the centrality of light to both life and society. We understand how sunlight drives photosynthesis, and we are directly involved in the study and applications of light-based technologies in communications, manufacturing, and medicine. As well stated in the inaugural Advanced Photonics perspective article by Eugene Arthurs, the future of photonics is bright. ${ }^{1}$

But while we-as scientists-need no convincing of the importance of our field, it is a mistake to take for granted that others share our enthusiasm and understanding. Outside the scientific communityamong members of the public, as well as within funding bodies and governments-the key role played by photonics in the infrastructure of modern society is greatly underappreciated.

I have witnessed this first hand for nearly ten years. To eventually obtain the United Nations proclamation of the year 2015 as the International Year of Light and Light-based Technologies, we had to work very hard since 2009 in order to explain to science diplomats and policy advisors what exactly photonics is and how it benefits society. I was constantly surprised how even the most senior officials were nearly always completely unaware of the way light formed the backbone of the internet and were only vaguely familiar with the way that photonics is used in fields such as energy, agriculture, and health. To get the attention of the United Nations, it was necessary to educate first and then to lobby. It was also necessary to be patient and to persevere!

The International Year of Light was viewed as a great success by UNESCO, and at the end of 2015, it became clear that the international photonics community had an opportunity to build on this momentum. Strongly supported by SPIE and other scientific societies, a consortium of partners worked with UNESCO to create an enduring legacy in the form of a permanent International Day of Light. This was proclaimed by UNESCO in 2017 and is now on the permanent calendar of UNESCO observances. Although the themes of the International Day of Light are broad, science and technology were certainly at the center of the arguments advanced to UNESCO. In fact, the day selected for the celebration was 16 May, the anniversary of the first operation of the laser by Ted Maiman in 1960 .

There are relatively few science observances within the United Nations system, and an International Day of Light is an extraordinary accomplishment. It is also a remarkable recognition of how light-based technologies are perceived as important to the concerns of the United Nations and its agencies. Indeed, the International Day of Light has the specific objective to improve the public understanding of how light and light-based technologies touch the daily lives of everybody and are central to the future development of the global society. All of us in photonics must surely agree that this is a tremendously worthwhile goal.

A question I am often asked, however, is what exactly should we do on the International Day of Light. There is no one answer, of course. There are many possibilities, and essentially every kind of activity that promotes light to any audience is to be encouraged. For example, light and optics are tremendous themes for public outreach and can be used to stimulate wider interest in science in general. Children are attracted to the many exciting visual aspects of light and color, and adults are

*Address all correspondence to John M. Dudley, E-mail: john.dudley@univ-fcomte.fr (C) 2019 SPIE and CLP. [DOI: 10.1117/1.AP.1.2.020501] interested in the underlying technologies and discussions of the many related career opportunities for their children. Discussing everyday optical effects, such as the color of the sky, clouds, and rainbows, never fails to interest people, and opens up opportunities to talk about the latest developments in optics and photonics research.

The broad theme of light makes it easy to combine International Day of Light activities with events in other fields of science and technology, and it is also possible to combine science outreach with cultural performance. Indeed, there are many advances in how photonics is being applied in this way, such as in dynamic mapping and light painting. There are also opportunities to explain the use of advanced optical technologies in fields such as art history, archaeology, and in the preservation of cultural heritage. Moreover, the theme of light allows us to raise awareness of what we can see when the lights are turned off, and the need to reduce unwanted light pollution - to appreciate the cosmos, as well as to save energy and improve health.

We have the opportunity with an International Day of Light to touch on even wider issues. The association with UNESCO readily allows consideration of how to build educational capacity, how to implement technological solutions in poorer regions of the world, and how to effectively address gender issues. These are themes that are sometimes difficult to include in a regular scientific conference, but they are ideal for an event held in the context of the International Day of Light.

In addition, we should not hesitate to engage on the political level. In fact, even after a year of effort at the end of 2015, we were really only beginning to connect the different sectors that need to work together to solve the global problems where photonics has the solutions. And we were also just beginning to learn how to effectively communicate with policymakers.

Scientists are very often puzzled by the failure of scientific evidence to influence policy, but it is important to appreciate that the policy environment involves input from many different areas. There is also often high turnover in government positions, so the same arguments have to be repeated frequently to new faces. But it is possible to make real progress, and in 2015, there were some remarkable political

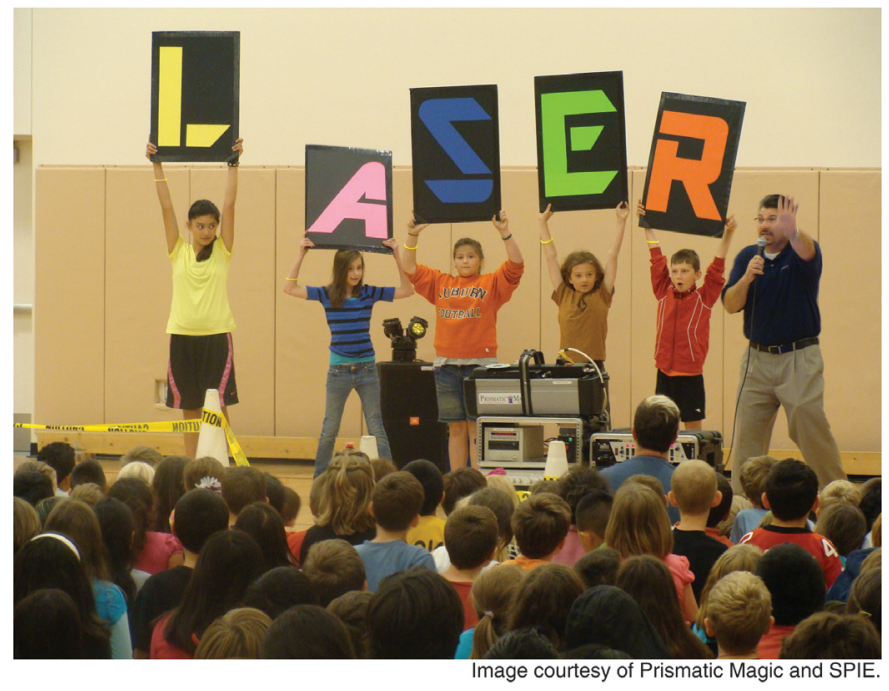


achievements with photonics being discussed in diverse forums-from the Parliament of Andorra to the Senate of the United States. ${ }^{2}$

An annual International Day of Light gives us the mandate and visibility to continue this effort. Although it may seem daunting to enter the political ecosystem of science, it is more important than ever that we do so if we wish to have influence. After all, when changes are made at policy level, then the research and education environment of a country can be changed (for better or worse!) for many years. It is vital that such policy decisions receive informed input from active and committed scientists, and if we in the field of photonics do not get involved to defend our own sector, then our place will be taken by others. As mentioned above, the policy environment is one that continually receives input from many different sectors, and this is something we must always bear in mind.

That said, we are very fortunate in that there is no shortage of concrete and accessible illustrations of how photonics has changed the world, and we just need to learn how to use these examples to press home our point. For example, with smartphones in the hands of more than a third of the world's population, it is easy to explain how technology changes lives, but we have to go a little further in discussing the long timescale needed from research to societal application. We also have to explain how applications that eventually become widespread sometimes have no relation with the initial research objectives. As Charles Townes said, "what doctor, wanting a new surgical tool as the laser has turned out to be, would have urged the study of microwave spectroscopy?"3 Now is the time to communicate this important message. If we can encourage more appreciation of the strategic importance of basic research, this will be beneficial to us all for many years to come.
Of course, making changes of any kind on a societal level requires patience and perseverance. But an International Day of Light comes around every year, and so we will have many opportunities. Although as individuals our actions may be limited, we are supported by an international network of scientific bodies such as SPIE who can help us in our efforts. We all have a role to play!

\section{References}

1. E. G. Arthurs, "Perspectives on the future of photonics: the best is yet to come," Adv. Photonics 1(1), 010501 (2019).

2. United Nations, General Assembly, "International Year of Light and Light-based Technologies, 2015: note by the Secretary-General," A/71/222, 27 July 2016, www.undocs.org/A/71/222 (accessed 9 March 2019).

3. C. H. Townes, How the Laser Happened: Adventures of a Scientist, Oxford University Press, New York (1999).

John M. Dudley is a professor of physics at the Université BourgogneFranche-Comté and the CNRS Institute FEMTO-ST in Besancon, France. His research covers broad areas of optical science, and he has published over 500 contributions in journals and conference proceedings and delivered over 120 invited talks. He was the president of the European Physical Society from 2013 to 2015, initiated and chaired the UN International Year of Light and Light-based Technologies 2015, and also chaired the follow-up annual UNESCO International Day of Light. He is a fellow of OSA, the IEEE, the IOP, and the EOS, and has won numerous awards, including the Médaille d'Argent of the French CNRS, prizes from societies SPIE, OSA, and IOP, as well as four honorary degrees. He was recently awarded the SPIE Harold E. Edgerton Award for 2019, recognizing his contributions to ultrashort pulse measurements in nonlinear fiber optics. 